\title{
MANUTENÇÃO DA INFECTIVIDADE DE TYMOVÍRUS EM EXTRATOS DE PLANTAS ${ }^{1}$
}

\author{
Maria Mércia Barradas ${ }^{2}$ \\ Fernando J. Sanhueza Salas ${ }^{3}$ \\ Ivan P. González Buitrón ${ }^{4}$
}

Recebido em 16-9-91. Aceito em 20-9-92.

RESUMO: Quatro isolados do vírus do mosaico da berinjela (EMV - "eggplant mosaic virus" - grupo tymovírus) foram armazenados a partir de extratos foliares de hospedeiras com sintomas sistêmicos. Os virus EMV-Al (isolado de Abelia), EMV-Sc (isolado da Escócia), -ts (estirpe-padrão) e VNBT (vírus da necrose branca do tomateiro), que induzem sintomas em Chenopodium amaranticolor, C. murale, C.quinoa (Família Chenopodiaceae) Datura stramonium, Lycopersicon esculentum e Nicotiana glutinosa (Solanaceae), foram conservados em extratos destas plantas, à temperatura ambiente, em geladeira e em congelador. A infectividade dos vírus, em diferentes períodos de armazenamento, foi testada em plantas de datura e glutinosa, para se determinar a longevidade in vitro. Constatou-se que, quando guardados em baixas temperaturas,os extratos preservam por mais tempo a infectividade dos vírus. No caso de datura e glutinosa, por exemplo, resultados positivos foram obtidos até 413 e 282 dias de armazenamento, respectivamente, em congelador. Entretanto, com relação às espécies de Chenopodium testadas, mesmo alguns extratos recém-preparados conduziram a resultados negativos, confirmando a presença de inibidores de infecçāo viral nestas plantas. Das três espécies, é sugerida a utilização apenas de C.quinoa para o preparo de extratos visando preservar estes vírus e, assim mesmo, por um período relativamente curto (entre 53 e 80 dias). A avaliação geral dos resultados mostra que, para os tymovírus estudados neste trabalho, é possível conservar a infectividade através da técnica de armazenamento de extratos foliares de plantas sistemicamente infectadas.

Palavras-chave: tymovírus, armazenamento em extratos, Solanaceae, Chenopodiaceae

1 - Trabalho apresentado no XLII Congresso Nacional de Botânica, Goiânia-GO. 2 - Seção de Virologia Fitopatológica e Fisiopatologia (SVFF), Instituto Biológico (IB), Caixa Postal 7119, CEP 01064-970, São Paulo, SP. Bolsista do CNPq (Pesq.) 3 - Bolsista do $\mathrm{CNPq}$ (Aperf.)

4 - Bolsista do CNPq (IC) 
ABSTRACT: Four isolates of EMV (eggplant mosaic virus - tymovirus group) were preserved in crude extracts from systemically-infected plants. EMV-Al (Abelia strain), EMV-Sc (Scottish strain), EMV-ts (type-strain) and TWNV (tomato white necrosis virus) which induce symptoms in Chenopodium amaranticolor, C. murale, C. quinoa (Family Chenopodiaceae), Datura stramonium, Lycopersicon esculentum and Nicotiana glutinosa (family Solanaceae) plants were maintened in leaf extrats obtained from these species. The extracts were kept at room temperature, at about $5+\mathrm{C}$ and at about $20+C$. Sap containing viruses were periodically inoculated in test-plants (datura and glutinosa) in order to determine the longevity in vitro. It was verified that viruses remained infective for longer periods if extratcs were kept at low temperatures as compared with those maintained at room temperature. In the case of sap juice from datura and glutinosa plants, EMV isolates remained infective respectivelly up to 413 and 282 days at about $-20+C$. However, many negative results were obtained with Chenopodium species even when freshly prepared leaf juice were used. This fact may be understood by the presence of virus inhibitors in these plants. Only C. quinoa is a valuable host to be used to preserve four EMV isolates, although for a short period (more than 53 and less than 80 days). The present paper reports the successful use of keeping infected leaf juices for preserving the infectivity of some tymoviruses.

Key-Words: tymoviruses, storage in leaf juices, Solanaceae, Chenopodiaceae

\section{Introdução}

Os tymovírus constituem um grupo de fitovírus que apresentam forma isométrica (25-30 nm de diâmetro), são bastante estáveis, atingem elevada concentração nas hospedeiras, são facilmente transmitidos por inoculação mecânica e, na natureza, transmitem-se por coleópteros (Koenig \& Lesemann, 1979, 1981; Francki et al., 1985; Hirth \& Givord, 1988; Brunt et al., 1990). A denominação tymovírus deriva do nome do vírus-padrão: vírus do mosaico amarelo do nabo ("turnip yellow mosaic VÍRUS"). O primeiro agente deste tipo isolado no Brasil, o vírus da necrose branca do tomateiro (VNBT), foi caracterizado como um isolado do vírus do mosaico da berinjela (EMV = "Eggplant Mosaic Vírus"), por Barradas (1983).

O estudo da estabilidade in vitro de vírus de plantas vem sendo realizado, na Seção de Virologia Fitopatológica e Fisiopatologia do Instituto Biológico, desde 1973, com a organização de uma viroteca, através da técnica de preservação de v'irus em tecidos foliares desidratados com $\mathrm{CaCl} 2$ anidro (Barradas \& Silberschmidt, 1973; Barradas, 1978, 1986).

Na seqüência de estuds sobre o armazenamento de vírus, deu-se início a experimentos para testar a manutenção da infectividade (longevidade in vitro) de alguns tymovírus em extratos foliares. Pretende-se, com esta solução alternativa, colaborar para diminuir as atividades de rotina, referentes às repicagens periódicas dos vírus em plantas hospedeiras. 


\section{Material e Métodos}

O material empregado (vírus e espécies hospedeiras) encontra-se relacionado nas tabelas 1 e 2 .

Os extratos foram preparados a partir de folhas de plantas com infecção sistêmica, na proporção de $1 \mathrm{~g}$ de folhas para $20 \mathrm{ml}$ de água destilada. Utilizou-se água destilada no preparo do extrato porque já se havia mostrado que não há necessidade do emprego de tampão para inóculos de vírus deste grupo, que são muito estáveis (Barradas, 1988). Os extratos brutos assim obtidos foram filtrados em gaze, e conservados em três diferentes condições: à temperatura ambiente $(\mathrm{A})$; em geladeira, a aproximadamente $5+\mathrm{C}(\mathrm{G})$; e em congelador, a aproximadamente $20+C$ (C). Para o armazenamento, amostras de $1,5 \mathrm{ml}$ de cada extrato foram acondicionadas em recipientes de vidro, com tampa de borracha. A infectividade dos tymovírus, nos extratos, foi detectada através de teste biológico, por inoculação mecânica em plantas de datura e glutinosa, que respondem com sintomas locais (47 dias após a inoculação) e/ou sistêmicos (7-15 dias após a inoculação), conforme Barradas (1983) e Barradas \& Colariccio (1986). Os ensaios de infectividade foram realizados imediatamente após o preparo dos extratos (tempo zero) e em diferentes períodos de armazenamento. Para cada vírus e período de armazenamento testados, foram utilizadas 15 plantas-teste (6 daturas e 9 glutinosas), sendo 5 para cada condição de temperatura.

As plantas inoculadas foram mantidas em casas-de-vegetação, sem controle de temperatura, para observação dos sintomas. Os controles constaram de plantas inoculadas" com extratos de folhas de plantas sadias, preservados nas mesmas condições.

Tabela 1 - Vírus empregados nas inoculações

\begin{tabular}{lll}
\hline Sigla & \multicolumn{1}{c}{ Nome } & \multicolumn{1}{c}{ Isolado } \\
\hline VNBT & $\begin{array}{l}\text { Vírus da necrose branca } \\
\text { do tomateiro }\end{array}$ & SVFF \\
EMV-Al & $\begin{array}{l}\text { "Eggplant mosaic virus" } \\
\text { (vírus do mosaico da }\end{array}$ & $\begin{array}{l}\text { "Abelia latent strain” } \\
\text { (estirpe latente isolada } \\
\text { de } \text { Abelia) }\end{array}$ \\
EMV-Scinjela) & $\begin{array}{l}\text { "Eggplant mosaic virus" } \\
\text { (vírus do mosaico da berinjela) }\end{array}$ & $\begin{array}{l}\text { "Scottish (estirpe isolada } \\
\text { na Escócia) }\end{array}$ \\
EMV-ts & "Eggplant mosaic virus" & “Type-strain" (estirpe \\
& (vírus do mosaico da berinjela) & padrão) \\
\hline
\end{tabular}


Tabela 2 - Espécies hospedeiras utilizadas

Espécie/Família Nome vulgar Local Sintoma*Sistêmico

Chenopodium

amaranticolor

quenopódio

MC,PN

MC,PN

Coste \& Reyn.

Quenopodiácea

Chenopodium murale $\mathrm{L}$.

PN

$\mathrm{MC}, \mathrm{PN}, \mathrm{Na}, \mathrm{RF}$

Quenopodiácea

Chenopodium quinoa

Willd.

quinoa

MC

MC,DF

Quenopodiácea

Datura stramonium L. datura

MC,PN

$\mathrm{CN}, \mathrm{Mo}$

Solanácea

Lycopersicon

esculentum

Mill.

tomateiro

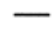

$\mathrm{CN}, \mathrm{MoBr}, \mathrm{FN}$

Solanácea

Nicotiana glutinosa $L$. glutinosa Solanácea

MC,MA, PN

$\mathrm{CN}, \mathrm{MoBr}, \mathrm{PN}$, DF,LP

* os sintomas aqui descritos foram baseados em Barradas (1983), que os descreveu para o VNBT. Quanto aos sintomas induzidos pelos outros três isolados do EMV, posteriormente se verificou que são muito semelhantes a estes.

$\mathrm{CN}=$ clareamento de nervuras; $\mathrm{DF}=$ deformaçäo foliar; $\mathrm{FN}=$ faixa-de-nervura; $\mathrm{LP}=$ "line patterns", $\mathrm{MC}=$ manchas cloróticas; $\mathrm{Mo}=$ mosaico $\mathrm{MoBr}=$ mosaico com manchas brancas; $\mathrm{MA}=$ manchas anulares; $\mathrm{Na}=$ nanismo; $\mathrm{PN}=$ pontos necróticos; $\mathrm{RF}=$ reduçāo da área foliar

\section{Resultados e Conclusões}

Os resultados estão mostrados nas tabelas 3-6. As tabelas 3 e 4 apresentam um resumo dos testes de infectividade do vírus em extratos foliares de solanáceas e quenopodiáceas, respectivamente. Nos extratos mantidos à temperatura ambiente, os vírus perdem a infectividade mais rapidamente que naqueles conservados em geladeira ou em congelador (Tabela 3). Além disso, comparando-se os resultados obtidos nestas duas últimas condições mencionadas, constata-se que maiores períodos de manutenção de infectividade são conseguidos com os extratos preservados 
Tabela 3 - Conservação de tymovírus em extratos foliares de Solanáceas

\begin{tabular}{|c|c|c|c|c|c|}
\hline Vírus & $\begin{array}{c}\text { Espécie } \\
\text { Armazenada }\end{array}$ & $\begin{array}{l}\text { Tipo de } \\
\text { Armazenamento }\end{array}$ & $\begin{array}{l}\text { Período Máximo de } \\
\text { Armazenamento } \\
\text { com Resultado } \\
\text { Positivo } \\
\text { (dias) }\end{array}$ & $\begin{array}{l}\text { Período Máximo de } \\
\text { Armazenamento } \\
\text { Testado (dias) }\end{array}$ & Resultados \\
\hline \multirow{3}{*}{ EMV-AL } & DS & $\begin{array}{l}\mathrm{A} \\
\mathrm{G} \\
\mathrm{C}\end{array}$ & $\begin{array}{l}304 \\
240 \\
413\end{array}$ & 413 & $\begin{array}{l}- \\
+ \\
+\end{array}$ \\
\hline & LE & $\begin{array}{l}\mathrm{A} \\
\mathrm{G} \\
\mathrm{C}\end{array}$ & $\begin{array}{l}44 \\
84 \\
84\end{array}$ & 84 & $\begin{array}{l}- \\
+ \\
+\end{array}$ \\
\hline & NG & $\begin{array}{l}\mathrm{A} \\
\mathrm{G} \\
\mathrm{C}\end{array}$ & $\begin{array}{l}240 \\
126 \\
282\end{array}$ & 282 & $\begin{array}{l}- \\
- \\
+\end{array}$ \\
\hline \multirow{3}{*}{ EMV-SC } & DS & $\begin{array}{l}\mathrm{A} \\
\mathrm{G} \\
\mathrm{C}\end{array}$ & $\begin{array}{l}304 \\
413 \\
413\end{array}$ & 413 & $\begin{array}{l}- \\
+ \\
+\end{array}$ \\
\hline & LE & $\begin{array}{l}\mathrm{A} \\
\mathrm{G} \\
\mathrm{C}\end{array}$ & $\begin{array}{l}44 \\
84 \\
84\end{array}$ & 84 & $\begin{array}{l}- \\
+ \\
+\end{array}$ \\
\hline & NG & $\begin{array}{l}A \\
G \\
C\end{array}$ & $\begin{array}{l}140 \\
126 \\
282\end{array}$ & 282 & $\begin{array}{l}- \\
+ \\
+\end{array}$ \\
\hline \multirow{3}{*}{ EMV-TS } & DS & $\begin{array}{l}\mathrm{A} \\
\mathrm{G} \\
\mathrm{C}\end{array}$ & $\begin{array}{r}79 \\
413 \\
413\end{array}$ & 413 & $\begin{array}{l}- \\
+ \\
+\end{array}$ \\
\hline & LE & $\begin{array}{l}\mathrm{A} \\
\mathrm{G} \\
\mathrm{C}\end{array}$ & $\begin{array}{l}44 \\
84 \\
84\end{array}$ & 84 & $\begin{array}{l}- \\
+ \\
+\end{array}$ \\
\hline & NG & $\begin{array}{l}\mathrm{A} \\
\mathrm{G} \\
\mathrm{C}\end{array}$ & $\begin{array}{l}126 \\
140 \\
282\end{array}$ & 282 & $\begin{array}{l}- \\
+ \\
+\end{array}$ \\
\hline \multirow{3}{*}{ VNBT } & DS & $\begin{array}{l}\mathrm{A} \\
\mathrm{G} \\
\mathrm{C}\end{array}$ & $\begin{array}{r}79 \\
304 \\
413\end{array}$ & 413 & $\begin{array}{l}- \\
+ \\
+\end{array}$ \\
\hline & LE & $\begin{array}{l}A \\
G \\
C\end{array}$ & $\begin{array}{l}44 \\
84 \\
84\end{array}$ & 84 & $\begin{array}{l}- \\
+ \\
+\end{array}$ \\
\hline & NG & $\begin{array}{l}\mathrm{A} \\
\mathrm{G} \\
\mathrm{C}\end{array}$ & $\begin{array}{l}240 \\
140 \\
282\end{array}$ & 282 & $\begin{array}{l}- \\
+ \\
+\end{array}$ \\
\hline
\end{tabular}

A - Temperatura ambiente

$\mathrm{G}$ - Geladeira (aproximadamente $5^{\circ} \mathrm{C}$ )

C - Congelador (aproximadamente $-20^{\circ} \mathrm{C}$ )

DS - Datura stramonium

LE - Lycopersicon esculentum

NG - Nicotiana glutinosa 
Tabela 4 - Conservação de tymovírus em extratos foliares de Quenopodiáceas

\begin{tabular}{|c|c|c|c|c|c|}
\hline Vírus & $\begin{array}{c}\text { Espécie } \\
\text { Armazenada }\end{array}$ & $\begin{array}{c}\text { Teste de } \\
\text { Infectividade do } \\
\text { Extrato recém- } \\
\text { preparado }\end{array}$ & $\begin{array}{c}\text { Tipo de } \\
\text { Armazenamento }\end{array}$ & $\begin{array}{c}\text { Período de } \\
\text { Armazenamento } \\
\text { Testado (dias), com } \\
\text { alguns Resultados } \\
\text { Positivos }\end{array}$ & $\begin{array}{c}\text { Período } \\
\text { Máximo de } \\
\text { Armaz. } \\
\text { Testado } \\
\text { (dias), com } \\
\text { Result. } \\
\text { Negativos }\end{array}$ \\
\hline \multirow{3}{*}{ EMV-Al } & $\mathrm{Ca}$ & - & $\begin{array}{l}\mathrm{A} \\
\mathrm{G} \\
\mathrm{C}\end{array}$ & $\begin{array}{l}* \\
* \\
*\end{array}$ & 30 \\
\hline & $\mathrm{Cm}$ & + & $\begin{array}{l}\mathrm{A} \\
\mathrm{G} \\
\mathrm{C}\end{array}$ & $\begin{array}{l}* * \\
30 \\
* *\end{array}$ & 71 \\
\hline & $\mathrm{Cq}$ & + & $\begin{array}{l}\mathrm{A} \\
\mathrm{G} \\
\mathrm{C}\end{array}$ & $\begin{array}{l}53 \\
53 \\
53\end{array}$ & 80 \\
\hline \multirow{3}{*}{ EMV-Sc } & $\mathrm{Ca}$ & - & $\begin{array}{l}\mathrm{A} \\
\mathrm{G} \\
\mathrm{C}\end{array}$ & $\begin{array}{l}* \\
* \\
*\end{array}$ & 30 \\
\hline & $\mathrm{Cm}$ & - & $\begin{array}{l}\mathrm{A} \\
\mathrm{G} \\
\mathrm{C}\end{array}$ & $\begin{array}{l}* \\
* \\
*\end{array}$ & 71 \\
\hline & $\mathrm{Cq}$ & + & $\begin{array}{l}\mathrm{A} \\
\mathrm{G} \\
\mathrm{C}\end{array}$ & $\begin{array}{l}53 \\
53 \\
53\end{array}$ & 80 \\
\hline \multirow{3}{*}{ EMV-Ts } & $\mathrm{Ca}$ & + & $\begin{array}{l}A \\
G \\
C\end{array}$ & $\begin{array}{l}* * \\
* * \\
* *\end{array}$ & 30 \\
\hline & $\mathrm{Cm}$ & + & $\begin{array}{l}\mathrm{A} \\
\mathrm{G} \\
\mathrm{C}\end{array}$ & $\begin{array}{l}* * \\
* * \\
30\end{array}$ & 71 \\
\hline & $\mathrm{Cq}$ & + & $\begin{array}{l}A \\
G \\
C\end{array}$ & $\begin{array}{l}53 \\
53 \\
53\end{array}$ & 80 \\
\hline \multirow{3}{*}{ VNBT } & $\mathrm{Ca}$ & - & $\begin{array}{l}\mathrm{A} \\
\mathrm{G} \\
\mathrm{C}\end{array}$ & $\begin{array}{l}* \\
* \\
*\end{array}$ & 30 \\
\hline & $\mathrm{Cm}$ & - & $\begin{array}{l}\mathrm{A} \\
\mathrm{G} \\
\mathrm{C}\end{array}$ & $\begin{array}{l}* \\
* \\
*\end{array}$ & 71 \\
\hline & $\mathrm{Cq}$ & + & $\begin{array}{l}\mathrm{A} \\
\mathrm{G} \\
\mathrm{C}\end{array}$ & $\begin{array}{l}53 \\
53 \\
53\end{array}$ & 80 \\
\hline
\end{tabular}

$\mathrm{A}=$ Temperatura ambiente

$\mathrm{G}=$ Geladeira $\left(3 \mathrm{a} 5^{\circ} \mathrm{C}\right)$

$\mathrm{C}=$ Congel ador $\left(-18 \mathrm{a}-20^{\circ} \mathrm{C}\right)$

$\mathrm{Ca}=$ Chenopodium amaranticolor

$\mathrm{Cm}=$ Chenopodium murale

$\mathrm{Cq}=$ Chenopodium quinoa

* = não determinado, visto que o teste inicial já havia sido negativo

** = inferior a 30 dias. 
em congelador. Observa-se que os períodos máximos de armazenamento testados foram 30, 71, 80, 84, 282 e 413 dias, para C. amaranticolor, C. murale, C. quinoa, L. Esculentum, N. Glutinosa e D. Stramonium, respectivamente (Tabelas 3 e 4). Nos três primeiros casos, os resultados foram negativos e, nos três últimos, positivos (considerando-se os tratamentos C e G). Não foi possível efetuar novos testes, pois os extratos haviam terminado. Os resultados, com relação a estas três últimas espécies, indicam que a infectividade dos vírus pode se manter, em extratos guardados na geladeira ou no congelador, por períodos maiores que aqueles assinalados na tabela 3 (84, 282 e 413 dias). Observa-se ainda, com relação aos extratos de solanáceas, que o número de plantas que responde positivamente ao ensaio de infectividade diminui com o tempo de armazenamento (Tabela 5). Quanto aos extratos de Chenopodium, a maioria dos testes de infectividade apresentou resultados negativos, com exceção de $C$. quinoa, mesmo para os extratos recém-preparados (Tabela 3) o que sugere a ocorrência de inibidores virais, substâncias estas já detectadas em diversas espécies do gênero (Smookler, 1971; Alberghina, 1976; Vicente et al., 1977).

Tabela 5 - Número de plantas - família Solanácea - que respondem à inoculação com o extrato armazenado por diferentes períodos (Número de plantas inoculadas $=15$ )

\begin{tabular}{llllllll}
\hline Extrato & Vírus & \multicolumn{6}{c}{$\begin{array}{l}\text { N de plantas com sintomas, de acordo com o } \\
\text { tempo de armazenamento do extrato (dias) }\end{array}$} \\
\cline { 3 - 8 } & & zero & 84 & 140 & 240 & 282 & 413 \\
\hline \multirow{2}{*}{ datura } & VNBT & 15 & 15 & 8 & 4 & 3 & 3 \\
& EMV-Al & 15 & 15 & 9 & 5 & 3 & 3 \\
& EMV-Sc & 13 & 14 & 4 & 5 & 3 & 3 \\
& EMV-ts & 15 & 13 & 6 & 5 & 5 & 3 \\
glutinosa & VNBT & 15 & 9 & 9 & 5 & 3 & $*$ \\
& EMV-Al & 14 & 14 & 8 & 4 & 4 & $*$ \\
& EMV-Sc & 15 & 8 & 6 & 4 & 3 & $*$ \\
& EMV-ts & 13 & 8 & 8 & 4 & 4 & $*$ \\
& & & & & & & $*$ \\
& VNBT & 14 & 11 & $*$ & $*$ & $*$ & $*$ \\
& EMV-Al & 14 & 11 & $*$ & $*$ & $*$ & $*$ \\
& EMV-Sc & 15 & 11 & $*$ & $*$ & $*$ & $*$ \\
& EMV-ts & 15 & 12 & $*$ & $*$ & $*$ & $*$ \\
\hline
\end{tabular}

(a) = total de plantas, nos três tratamentos $(\mathrm{A}, \mathrm{G}, \mathrm{C})$

(b) = nāo estāo apresentados resultados de vários testes feitos em período intermediários a estes mostrados

$*$ = teste nāo realizado. 
Com o objetivo de tentar favorecer a indução de sintomas, em plantas de datura e glutinosa, os extratos provenientes de C. amaranticolor, tanto os recémpreparados como aqueles mantidos em congelador ( 28 dias), foram diluídos 100 vezes e inoculados nestas espécies. No primeiro caso, surgiram pouquíssimas lesões locais nas plantas e, no segundo, o resultado foi negativo, indicando que o inibidor precisa ser mais diluído, para ter seu efeito minimizado e/ou que este inibidor age sobre as plantas hospedeiras (datura e glutinosa), impedindo a infecção (Vicente et al., 1977). Já é fato bastante conhecido que os inibidores não impedem a ação dos vírus na própria planta onde ocorrem, mas sim em outras espécies, sem relação taxonômica com a planta original. É possível que resultados positivos tivessem sido obtidos, no caso de extratos de $C$. amaranticolor $e C$. murale, se a infectividade tivesse sido testada nas mesmas espécies, ou em espécies próximas. Assim, não é adequado tentar conservar vírus em extratos de plantas que contêm inibidores, pois sempre haverá dificuldades relacionadas aos testes de infectividade, considerando que deverão ser realizados, preferencialmente, nas mesmas espécies empregadas no preparo dos extratos.

De acordo com a tabela 6, onde se procurou incluir todos os tymovírus conhecidos, os maiores valores de longevidade in vitro (LIV) não ultrapassam 180 dias, para extratos conservados em geladeira ou em congelador, e foram determinados para os vírus APLV, DMV e OYMV. Quando o armazenamento é feito à temperatura ambiente, o período de preservação dos tymovírus é menor, variando de 1 a 100 dias, dependendo do agente. Com relação ao EMV, Gibbs \& Harrison (1973) relatam que a LIV, à temperatura ambiente, é de apenas 7 dias (Tabela 6), sem informar a espécie usada no preparo de extrato. Os resultados aqui expostos (Tabela 3) demonstram que os quatro isolados do EMV estudados suportam períodos mais longos de armazenamento, à temperatura ambiente, sem perder a infectividade (pelo menos 44, 77 e 126 dias, para tomateiro, datura e glutinosa, respectivamente).

Consultando a literatura (Tabela 6), chama a atenção o fato de que a maioria dos trabalhos não menciona a planta utilizada no preparo dos extratos, o que é uma falha, pois os dados obtidos no presente trabalho (Tabelas 3 e 4) confirmam que, de acordo com a espécie botânica empregada, a longevidade in vitro dos vírus varia.

Técnicas de preservação de vírus são bastante úteis no estudo destes patógenos, principalmente quando se quer diminuir a freqüência das repicagens sucessivas em plantas hospedeiras, procedimento que pode favorecer a contaminação e exige muita mão-de-obra. Daí a importância da conservação em extratos foliares, técnica usada neste trabalho, bastante simples, e que, pelo menos para os tymovírus aqui relatados, conduziu a bons resultados, quando comparados aos dados da literatura (Tabela 6).

O armazenamento a $-20+C$ de extratos foliares de plantas com infecção sistêmica, como um processo de preservação de fitovírus, é muito utilizado para os vírus que se transmitem por inoculação mecânica e que são relativamente estáveis (Noordam, 1973; Purcifull et al., 1975; Hill, 1984). Uma condição indispensável 
Tabela 6 - Informaçōes sobre a longevidade in vitro de vírus do grupo tymovírus (Dados obtidos da literatura)

\begin{tabular}{|c|c|c|c|c|c|}
\hline Vírus & Sigla & $\begin{array}{l}\text { Longevid } \\
\text { in vitr } \\
\text { (dias) }\end{array}$ & dade & $\begin{array}{l}\text { Planta usada no } \\
\text { Preparo do } \\
\text { Extrato }\end{array}$ & $\begin{array}{c}\text { Referência } \\
\text { Bibliográfica }\end{array}$ \\
\hline $\begin{array}{l}\text { "Andean potato latent v." (vírus } \\
\text { latente da batata dos Andres) }\end{array}$ & APLV & $\begin{array}{l}2-7 \\
180\end{array}$ & $\begin{array}{l}\text { (A) } \\
\text { (G.C) }\end{array}$ & - & $\begin{array}{l}\text { Gibbs et } \\
\text { al., } 1966\end{array}$ \\
\hline $\begin{array}{l}\text { "Belladonna mottle v."(vírus } \\
\text { do mosqueado da beladona) }\end{array}$ & BMV & $5-21$ & (A) & - & Paul, 1971 \\
\hline $\begin{array}{l}\text { "Cacao yellow mosaic v."(vírus } \\
\text { do mosaico amarelo do } \\
\text { cacaueiro) }\end{array}$ & CaYMV & $\begin{array}{l}16-32 \\
100\end{array}$ & $\begin{array}{l}\text { (A) } \\
(\mathrm{G})\end{array}$ & $\begin{array}{l}\text { Theobroma } \\
\text { cacao }\end{array}$ & Brunt, 1970 \\
\hline $\begin{array}{l}\text { "Clitoria yellow vein v."(vírus } \\
\text { da nervura amarela de Clitoria) }\end{array}$ & ClYVV & 21 & (A) & $\begin{array}{l}\text { Nicotiana } \\
\text { clevelandii }\end{array}$ & $\begin{array}{l}\text { Bock \& } \\
\text { Guthrie, } 1977\end{array}$ \\
\hline $\begin{array}{l}\text { "Desmodium yellow mottle v." } \\
\text { (vírus do mosqueado amarelo de } \\
\text { Desmodium) }\end{array}$ & DeYMV & $38-44$ & (A) & $\begin{array}{l}\text { Phaseolus } \\
\text { vulgaris }\end{array}$ & Scott, 1976 \\
\hline $\begin{array}{l}\text { "Dulcamara mottle v." (vírus do } \\
\text { mosqueado de dulcamara) }\end{array}$ & DMV & $\begin{array}{l}2-7 \\
180\end{array}$ & $\begin{array}{l}\text { (A) } \\
(\mathrm{G}, \mathrm{C})\end{array}$ & - & $\begin{array}{l}\text { Gibbs et } \\
\text { al., } 1966\end{array}$ \\
\hline $\begin{array}{l}\text { "Eggplant mosaic v." (vírus do } \\
\text { mosaico da berinjela) }\end{array}$ & EMV & 7 & (A) & - & $\begin{array}{l}\text { Gibbs \& } \\
\text { Harrinson, } \\
1973\end{array}$ \\
\hline $\begin{array}{l}\text { "Erysimum latent v." (vírus } \\
\text { latente de Erysimum) }\end{array}$ & EryLV & 20 & (A) & $\begin{array}{l}\text { Sinapis } \\
\text { alba }\end{array}$ & $\begin{array}{l}\text { Shukla \& } \\
\text { Gough, } 1980\end{array}$ \\
\hline $\begin{array}{l}\text { "Kennedya yellow mosaic v." } \\
\text { (vírus do mosaico amarelo de } \\
\text { Kennedya) }\end{array}$ & KYMV & $10-100$ & (A) & $\begin{array}{c}\text { Pea } \\
\text { sativum }\end{array}$ & Gibbs, 1978 \\
\hline $\begin{array}{l}\text { "Mellon rugose mosaic v." } \\
\text { (vírus do mosaico rugoso do } \\
\text { melāo) }\end{array}$ & MRMV & - & - & - & $\begin{array}{l}\text { Jones et } \\
\text { al., } 1986\end{array}$ \\
\hline $\begin{array}{l}\text { "Okra mosaic v." (vírus do } \\
\text { mosaico do quiabeiro) }\end{array}$ & OkMV & $7-9$ & (A) & $\begin{array}{l}\text { Hibiscus } \\
\text { esculentus }\end{array}$ & $\begin{array}{l}\text { Givord \& } \\
\text { Koenig, } 1974\end{array}$ \\
\hline $\begin{array}{l}\text { "Ononis yellow mosaic v." (vírus } \\
\text { do mosaico amarelo de Ononis) }\end{array}$ & OYMV & $\begin{array}{l}14 \\
180\end{array}$ & $\begin{array}{l}\text { (A) } \\
(\mathrm{G}, \mathrm{C})\end{array}$ & - & $\begin{array}{l}\text { Gibbs et } \\
\text { al., } 1966\end{array}$ \\
\hline $\begin{array}{l}\text { "Passion fruit yellow mosaic v." } \\
\text { (vírus do mosaico amarelo do } \\
\text { maracujá) }\end{array}$ & PYMV & 8 & (A) & - & $\begin{array}{l}\text { Crestani } \\
\text { et al., } 1986\end{array}$ \\
\hline "Peanut yellow mottle v." (vírus & PeYMV & 22 & (A) & - & Lana, 1980 \\
\hline
\end{tabular}


Cont. Tabela 6.

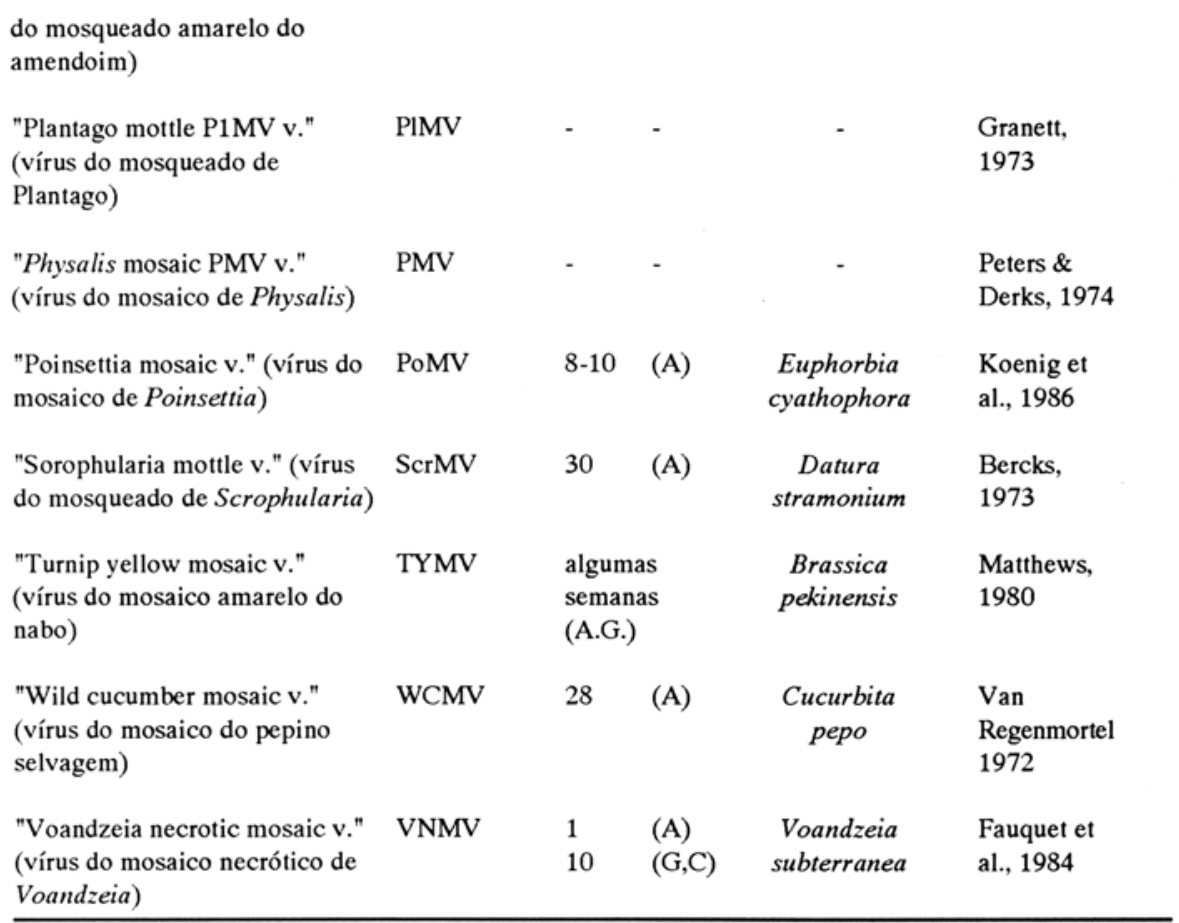

- = dados não encontrados

$\mathrm{A}=$ temperatura ambiente

$\mathrm{G}=$ temperatura variando de 0 a $5^{\circ} \mathrm{C}$

$\mathrm{C}=$ temperatura variando de $-15 \mathrm{a}-20^{\circ} \mathrm{C}$

para que a infectividade dos vírus assim armazenados se mantenha consiste no fato de descongelar a amostra apenas uma vez, no momento do ensaio (Noordam, 1973; Hill, 1984). Por isso, é importante preparar diversas amostras, para que períodos diferentes de armazenamento possam ser testados, como foi feito neste trabalho.

1 - A técnica de manutenção de fitovírus, em extratos foliares, pode ser considerada um processo alternativo de preservação, pelo menos para vírus bastante estáveis, como é o caso do grupo em questão (tymovínus).

2 - Os tymovírus estudados mantêm sua infectividade por um período de até 413 dias, em alguns casos, quando conservados em extratos de sola náceas, porém o mesmo não ocorre com extratos preparados a partir de quenopodiáceas.

3 - O armazenamento de extratos a baixas temperaturas é mais eficiente na manutenção da infectividade destes fitovírus do que à temperatura ambiente.

4 - O período máximo de preservação (LIV) que estes tymovírus suportam depende da espécie hospedeira empregada no preparo do extrato. 


\section{Referências Bibliográficas}

ALBERGHINA, A. 1976. The inhibitory activity of extracts of Chenopodium amaranticolor leaves on the infection by tobacco necrosis virus. Phytopath. Z., Berlin, 87: 17-27.

BARRADAS, M.M. 1978. Organização de uma coleção de vírus fitopatogênicos em tecidos desidratados com cloreto de cálcio. Biológico, São Paulo, 44(9): 221230.

BARRADAS, M.M. 1983. Caracterização do vírus da necrose branca do tomateiro (VNBT) e sua identificação como um tymovírus. Tese de Doutoramento/ Instituto de Biociências/USP. São Paulo, 161p.

BARRADAS, M.M. 1986. Manutenção da coleção de vírus fitopatogênicos da Seção de Virologia Fitopatológica e Fisiopatologia (SVFF). Summa Phytopathologica, Piracicaba, 12 (1/2): 25 (Resumo).

BARRADAS, M.M. 1988. Efeito de diferentes tampões na infectividade do vírus da necrose branca do tomateiro (VNBT). p. 175. In: Resumos do $4^{2}$ Encontro Nacional de Virologia, 258 p. (São Lourenço, MG, 26 a 30 de Outubro de 1988).

BARRADAS, M.M. \& K.M. SILBERSCHMIDT. 1973. Conservação de vírus vegetais em tecidos secos de folhas. Arq. Inst. Biol., São Paulo, 44 (4): 375-379.

BARRADAS, M.M. \& A. COLARICCIO. 1986. Inclusões citoplasmáticas em plantas de Datura stramonium inoculadas com diferentes isolados do vírus do mosaico da berinjela (tymovirus). Arq. Inst. Biol., São Paulo, 53 (1/4): 75-79.

BERCKS, R. 1973. Scrophularia mottle virus. C.M.I./A.A.B. Descriptions of Plant Viruses, Wales, $\mathrm{n}^{2} 11$.

BOCK, K.L. \& E.J. GUTHRIE. 1977. Clitoria yellow vein virus. C.M.I./A.A.B. Descriptions of Plant Viruses, Wales, $\mathrm{n}^{2} 171$.

BRUNT, A.A. 1970. Cacao yellow mosaic virus. C.M.I./A.A.B. Descriptions of Plant Viruses, Wales, $\mathrm{n}^{2} 11$.

BRUNT, A.; K. CRABTREE; A. GIBBS. 1990. Viruses of Tropical Plants. Wallingford, C.A.B. International, 707p.

CRESTANI, O.A.; E.W. KITAJIMA; M.T. LIN; V.L.A. MARINHO. 1986. Passion fruit mosaic virus, a new tymovirus found in Brazil. Phytopathology, St. Paul, 76 (9): 951-955.

FAUQUET, C.; A. MONTSARRAT; J.C. THOUVENEL. 1984. Voandzeia necrotic mosaic virus. C.M.I./A.A.B. Descriptions of Plant Viruses, Wales, $\mathrm{n}^{2} 279$.

FRANCKI, R.I.B.; R. MILNE; T. HATTA. 1985. Atlas of Plant Viruses. Vol. 1. Boca Raton, CRC Press, 222p.

GIBBS, A.J. 1978. Kennedya yellow mosaic virus. C.M.I./A.A.B. Descriptions of Plant Viruses, Wales, $\mathrm{n}^{2} 193$.

GIBBS, A.J. \& B.D. HARRISON. 1973. Eggplant mosaic virus. C.M.I./A.A.B. Descriptions of Plant Viruses, Wales, $\mathrm{n}^{2} 124$.

GIBBS, A.J.; E. HECHT-POINAR; R.D. WOODS; R.K. MCKEE. 1966. Some properties of three related viruses: Andean potato latent, dulcamara mottle and ononis yellow mosaic. J.gen.Microbiol., London, 44: 177-193. 
GIVORD, L. \& L. KOENIG. 1974. Okra mosaic virus. C.M.I./A.A.B. Descriptions of Plant Viruses, Wales, $\mathrm{n}^{2} 128$.

GRANETT, A.L. 1973. Plantago mottle virus, a new member of the tymovirus group. Phytopathology, St. Paul, 63: 1313-1316.

HILL, S.A. 1984. Methods in Plant Virology. Oxford, Blackwell Sc. Publ., 167p.

HIRTH, L. \& L. GIVORD. 1988. Tymovinuses. p. 163-212, In: The Plant Viruses, vol. 3 (KOENIG, R., ed.). Plenum Publishing Corporation.

JONES, P.; S.B. ANGOOD; J.M. CARPENTER. 1986. Melon rugose virus, the cause of a disease of watermelon and sweet melon. Ann.appl.Biol., Wellesbourne, 108: 303-307.

KOENIG, L. \& D.-E. LESEMANN. 1979. Tymovirus group. C.M.I./A.A.B. Descriptions of Plant Viruses, Wales, $\mathrm{n}^{2} 214$.

KOENIG, L. \& D.-E. LESEMANN. 1981. Tymoviruses. p.33-60, In: Comparative Diagnosis of Viral Diseases, vol. IV (KURSTAK, E., ed.). Elsevier, NorthHolland Biomedical Press.

KOENIG, L.; D.-E. LESEMANN; R.W. FULTON. 1986. Poinsettia mosaic virus. C.M.I./A.A.B. Descriptions of Plant Viruses, Wales, $\mathrm{n}^{2} 311$.

LANA, A.F. 1980. Properties of a virus occurring in Arachis hypogea in Nigeria. Phytopath. Z., Berlin, 97: 169-178.

MATTHEWS, R.E.F. 1980. Turnip yellow mosaic virus. C.M.I./A.A.B. Descriptions of Plant Viruses, Wales, $\mathrm{n}^{2} 230$.

NOORDAM, D. 1973. Identification of Plant Viruses. Methods \& Experiments. Wageningen, Centre for Agricultural Publishing and Documentation, 207p.

PAUL, H.L. 1971. Belladonna mottle virus. C.M.I./A.A.B. Descriptions of Plant Viruses, Wales, $n^{2} 52$.

PETERS, D. \& A.F.L.M. DERKS. 1974. Host range and some properties of Physalis mosaic virus, a new virus of the turnip yellow mosaic virus group. Neth. J.Pl.Path., Wageningen, 80: 124-132.

PURCIFULL, D.E.; S.R. CHRISTIE; D.L. BATCHELOR. 1975. Preservation of plant virus antigens by freeze-drying. Phytopathology, St. Paul, 65 (11): 12021205.

SCOTT, H.A. 1976. Desmodium yellow mottle virus. C.M.I./A.A.B. Descriptions of Plant Viruses, Wales, $\mathrm{n}^{\circledR} 168$.

SHUKLA, D.D. \& K.H. GOUGH. 1980. Erysimum latent virus. C.M.I./A.A.B. Descriptions of Plant Viruses, Wales, $\mathrm{n}^{2} 222$.

SMOOKLER, M.M. 1971. Properties of inhibitors of plant virus infection occurring in leaves of species in the Chenopodiales. Ann.appl.Biol., Wellesbourne, 69: $157-168$.

VAN REGENMORTEL, M.H.V. 1972. Wild cucumber mosaic virus. C.M.I./A.A.B. Descriptions of Plant Viruses, Wales, $\mathrm{n}^{2} 105$.

VICENTE, M.; A. NORONHA; E. COLAMARINO. 1977. Modo de ação de um inibidor de virus fitopatogênicos extraido das folhas de Chenopodium amaranticolor Coste \& Reyn. Arq.Inst.Biol., São Paulo, 44 (4): 229-234. 